\title{
Ir a comer en el mercado: Aprovisionamiento, consumo y restauración en la transformación de dos modelos de promoción de los mercados urbanos (Barcelona y Madrid) / Eating in the food market: Supply, consumption and restaurants in the transformation of two different models promoting urban markets (Barcelona and Madrid)
}

\author{
F. Xavier Medina \\ Cátedra UNESCO de Alimentación, Cultura y Desarrollo. Facultad de Ciencias de la Salud. Universitat Oberta de Catalunya (UOC). España/Spain \\ fxmedina@uoc.edu
}

Recibido / Received: 26/11/2016

Aceptado / Accepted: 13/09/2017

\section{RESUMEN}

Este artículo reflexiona sobre las nuevas situaciones de los mercados en tanto que espacios públicos y sobre las actuales intervenciones en el contexto de nuevas demandas urbanas, atendiendo especialmente al papel de los mercados en tanto que espacios donde proveerse de comida y, directamente, donde comer. La nueva promoción de los mercados ha llevado a sus instituciones responsables (públicas y privadas) a hacer de algunos de ellos instrumentos de nuevos proyectos urbanos (ligados a menudo al turismo) que conjugan el aprovisionamiento con la restauración y el ocio, con el consumo alimentario in situ. A partir de metodologías cualitativas, en este artículo analizaremos los dos principales modelos existentes actualmente en España de promoción y de gestión de los mercados urbanos, los de Barcelona y Madrid, a través del estudio de sus dos principales mercados bandera: la Boquería y San Miguel.

Palabras clave: mercados, restauración, espacios urbanos, Barcelona, Madrid.

\section{ABSTRACT}

This article reflects on the new urban food market challenges. Urban food markets must be observed as public spaces, and the subject of different current interventions in the context of new urban demands, with special attention to the role of markets as spaces to eat in situ. The new development of markets has led its institutions responsible (public and private) to make some instruments of new urban projects (often linked to tourism) that combine the provision with catering and leisure, with food consumption in the same market space. Using qualitative methodologies, in this article we will discuss about the two main models existing currently in Spain for the promotion and management of urban markets, Barcelona and Madrid, through the study of its two main markets: La Boquería and San Miguel.

Keywords: Food markets, restaurants, urban spaces, Barcelona, Madrid.

\footnotetext{
*Autor para correspondencia / Corresponding author: Medina, X. Cátedra UNESCO de Alimentación, Cultura y Desarrollo, Estudios de Ciencias de la Salud, Universitat Oberta de Catalunya (UOC), Rambla del Poblenou, 156, 08018 Barcelona, España
}

Sugerencia de cita / Suggested citation: Medina, X. (2018). Ir a comer en el mercado: Aprovisionamiento, consumo y restauración en la transformación de dos modelos de promoción de los mercados urbanos (Barcelona y Madrid). Revista Española de Sociología, 27 (2), 267-280. 


\section{INTRODUCCIÓN}

Algunos mercados urbanos -especialmente aquellos situados en los centros históricos de determinadas ciudades - se han convertido en las últimas dos décadas en un reclamo cultural y turístico de primer orden. La posibilidad de sentir el pulso de una sociedad, de acercarse a sus gentes y a sus productos, ha favorecido el hecho de que un mayor número de personas, locales, pero también turistas en un cada vez mayor número, encuentren en estos espacios un atractivo singular que los hace dignos de ser visitados.

Hablamos, en el caso de España, principalmente de los mercados urbanos cubiertos, situados a menudo en construcciones de una cierta relevancia patrimonial que suman su valor arquitectónico al ya de por sí importante atractivo del mercado (Medina, 2015). La Boquería o Sant Antoni en Barcelona, San Miguel en Madrid, el Mercado de Colón en Valencia 0 el de la Ribera en Bilbao son ejemplos suficientes. Tanto es así, que los mercados no únicamente han despertado el interés de los visitantes y de los turistas, sino también el de las autoridades locales, que han visto — están viendo — en los mercados un potencial cada vez mayor de oferta y de atracción para locales y foráneos. Dicha atracción está jugando a favor de un cada vez más visible fenómeno de gentrificación, entendido este término como la revalorización y consecuente transformación experimentada por determinadas áreas urbanas, y que acaban teniendo consecuencias significativas en el tejido social de la zona en cuestión (cf. Slater, 2012). Un fenómeno de gentrificación que se da, entre otras formas, a nivel comercial y que, como señalan Hernández Cordero y Andreeva, (2016: 148 y ss.): “( ...) se caracteriza por desentrañar la forma en que la venta al por menor es desplazada por establecimientos de un estatus más alto que satisfacen la demanda de la clase media urbana. A este tipo de gentrificación se ha prestado poca atención y se ha estudiado como parte 0 consecuencia del proceso de revalorización urbana". En este sentido, se acostumbra a destacar especialmente su parte positiva, aquella que acaba con el deterioro del área en cuestión, pero no el desplazamiento de tipos de comercio y de clientela a otras áreas y/o la homogeneización 0 excesiva especialización de otras.
Dentro de este panorama, los mercados, en función de un proceso continuado de renegociación de sus usos y espacios, están adaptando también sus funcionalidades y sus servicios a públicos más amplios y a actividades más variadas, y que van desde la presentación 0 implementación de campañas públicas de diversa índole (culturales, nutricionales, gastronómicas, promocionales, etc.) hasta la atracción de visitantes a diferentes horas del día en función de ofertas concretas, entre las cuales las gastronómicas tienen un especial sentido. Así, el despliegue de aulas gastronómicas, salas de cata 0 talleres, está cada vez más a la orden del día.

Por otro lado, el reto turístico se encuentra cada vez más presente. Determinados mercados se encuentran hoy en día entre los activos culturales más visitados en sus ciudades. Este hecho ha llevado a las autoridades locales y a las responsables de los mercados a idear estrategias que permitan gestionar estos flujos turísticos y a evitar los conflictos que en ocasiones emergen entre visitantes, vendedores y público (Black, 2007; Medina, 2008).

En las líneas que siguen intentaremos establecer algunas consideraciones sobre diferentes aspectos relacionados con los mercados urbanos a través de los dos principales modelos existentes actualmente en España de promoción y de gestión de los mismos: los de Barcelona y Madrid.

Dentro de un continuum de renegociación de las necesidades urbanas en relación con los mercados locales, se pueden observar actualmente los efectos de una concertación entre agentes públicos y privados para renovar utilizaciones y espacios, y todo ello dentro de una dinámica indisociable tanto de la refuncionalización del espacio urbano como del papel de los mercados en si mismos. En este sentido, vemos cómo en el caso de Barcelona, y a través de su gestión pública desde el Institut Municipal de Mercats de Barcelona (IMMB), dependiente del ayuntamiento, se ha apostado por una red de mercados fuerte, con una gestión pública común y ligada principalmente al aprovisionamiento, con una presencia importante, aunque secundaria, de lugares de restauración en los mercados mismos.

En Madrid, por otro lado, se ha convertido algunos de sus mercados más emblemáticos en lu- 
gares de ocio y restauración directamente ligados al turismo y/o al ocio gastronómico, mientras que el factor "aprovisionamiento" ha quedado relegado, e incluso en algunos casos (el mismo mercado de San Miguel, como caso extremo, pero también en San Antón o San Bartolomé), es más bien simbólico. Vemos a través de ambos modelos que estos espacios públicos dedicados al comercio están redefiniendo sus actividades, sus retos y oportunidades, sus estructuras y espacios y sus funciones sociales para adaptarse tanto a una demanda social cambiante como a la presión socioeconómica externa, al mismo tiempo que responden a políticas de gestión urbana que, a pesar de estar íntimamente ligadas, difieren ampliamente en su radio de acción y en sus consecuencias. Dentro de este panorama general, la utilización de estos espacios más allá de su función de abastecimiento, y en tanto que lugares de restauración in situ, nos ofrece interesantes posibilidades de reflexión.

En las líneas que siguen, analizaremos los casos de los dos principales mercados de Barcelona y Madrid. Tanto la Boquería como San Miguel son lo que se ha dado en llamar "mercados bandera", principales en ambos casos, centrales y atractivos para el visitante (más allá del comprador más 0 menos habitual) y que, si bien se trata de casos específicos dentro del panorama mercadal de ambas ciudades, nos muestran a las claras el tipo de políticas locales y de gestión que desde las distintas administraciones se está llevando a cabo en relación con los mercados en ambas ciudades. Dentro de este panorama, la práctica de comer en los mercados ha acompañado la transformación de los mismos, y se encuentra dentro de un continuum de modernización y de rentabilidad de los mercados impulsado desde las administraciones mismas, y que está transformando de manera relativamente rápida tanto los mercados en sí mismos como su relación con el entorno urbano del cual forman parte.

\section{METODOLOGÍA}

Teniendo en cuenta como punto de partida la afirmación de Denzin y Lincoln (1994) sobre el hecho de que una investigación cualitativa se centra principalmente en estudios de casos específicos, este artículo se plantea como tal y se basa en una investigación todavía no finalizada, llevada a cabo en Barcelona y Madrid entre los años 2012 y 2017, en diferentes fases, más continuadamente en Barcelona, con alrededor de treinta visitas específicas durante este período, y de manera más discontinua en Madrid, con doce visitas en el momento de escribir este artículo. Las visitas a ambos mercados se han distribuido a lo largo del año, seleccionando, de todos modos, en base a nuestros intereses, mayores frecuencias en determinadas épocas de especial significación turística — periodo estival, semana santa, puentes.

Las visitas a ambos mercados se realizaron a horas diferentes, intentando cubrir la mayor parte del espectro horario. Cada visita tuvo una duración diferente, pero la mayoría duró entre 3 y 5 horas. Se proporciona solo información básica sobre los informantes para mantener su confidencialidad. En el artículo se incluyen también citas de charlas informales celebradas fuera del espacio físico del mercado y relacionadas con su experiencia en el mismo, para apoyar el análisis expuesto.

La investigación se ha centrado principalmente en ambos mercados, pero en un marco más amplio de interés que abarca los sistemas de mercado de ambas ciudades. Epistemológicamente este estudio se construye desde el pragmatismo metodológico que tiene en cuenta la iniciativa y flexibilidad del investigador y del investigado (Domínguez y Coco, 2000) y fortalece las redes sociales y el compromiso social (Montañés, 2009).

La metodología empleada ha sido principalmente cualitativa y de base etnográfica: observación participante, entrevistas en profundidad semiestructuradas a paradistas, gestores, usuarios, visitantes y turistas en ambos mercados.

La observación participante ha sido una de las técnicas principales utilizadas para la recogida de datos durante la investigación. Esta técnica, según Taylor y Bogdan (1998), es una de las más útiles y comunes en estudios sociales cualitativos. Estas observaciones han hecho posible abordar la cotidianeidad de ambos mercados y sus actividades, así como las diferentes perspectivas e intereses de los protagonistas (Krane y Baird, 2005). Se ha hecho 
uso del cuaderno de campo, en tanto que elemento de recogida de impresiones instantánea, que nos ha ayudado a plasmar determinadas situaciones y sensaciones in situ. Alguna de ellas se reproduce directamente en este artículo, citada directamente del cuaderno de campo.

Del mismo modo, la elección de informantes clave (Guasch, 1997; Woods, 1986) ha sido un factor importante para establecer vínculos con los participantes en los diferentes contextos y, a su vez, para tener acceso a más informantes.

Durante el trabajo de campo se llevaron a cabo entrevistas formales e informales con el fin de completar la información recopilada durante la fase de observación participante del estudio. Las entrevistas etnográficas fueron esenciales para explorar la información recabada durante la observación, y muy útiles en la obtención de informaciones en profundidad (Krane y Baird, 2005; Woods, 1986). Esto hizo posible poder estudiar los datos desde diferentes ángulos. Los informantes, de ambos sexos y distintos rangos de edad, correspondían a tres tipologías distintas: a) usuarios/as y turistas de/en ambos mercados, en distintas franjas horarias; b) empresarias/os y trabajadoras/es de ambos mercados; $\mathrm{y} \mathrm{c}$ ) personal de la administración y/o gestión de los mercados.

Las entrevistas formales fueron semiestructuradas y se llevaron a cabo con la ayuda imprescindible de un guión previo, tratando de anticipar las necesidades y los problemas relacionados con la investigación (Kvale, 2007). Estas conversaciones se basaron en una combinación de flexibilidad y direccionalidad, cosa que conduce a una entrevista abierta multidireccional. Esto facilitó la recolección de datos con informaciones que no habían sido previamente identificadas (Krane y Baird, 2005). Sin embargo, hay que contar siempre con el hecho de que el entrevistado influye de manera determinante en la estructura de la conversación y lo que en ella se discute (Woods, 1986).

\section{BARCELONA Y MADRID: POLÍTICAS PÚBLICAS EN RELACIÓN CON LOS MERCADOS URBANOS \\ BARCELONAY MADRID: POLITICAS PUBLICAS EN}

Tanto Barcelona como Madrid han desarrollado a lo largo de las últimas décadas políticas específi- cas para la promoción y la gestión de sus mercados urbanos. En el caso de Barcelona, desde mediados de los años ochenta se observa ya la voluntad de actualizar-modernizar y relanzar los mercados de la ciudad dentro de una política comercial con visión de conjunto en la que se decide apostar por este tipo de espacios - que ya en ese momento comienzan a estar afectados por presiones socioeconómicas de distinto nivel, incluyendo la implantación cada vez más numerosa de supermercados y/o grandes superficies-en tanto que estructuras comerciales de proximidad, pero también en tanto que ejes urbanos vertebradores de los distintos barrios.

Como consecuencia de ello, se crea el Institut Municipal de Mercats de Barcelona (IMMB). Creado en 1991 por el Ayuntamiento de Barcelona, el IMMB nació como un organismo autónomo con el mandato de promover los mercados municipales en tanto que espacios urbanos de titularidad y de gestión pública, formada por representantes de los comerciantes, del ayuntamiento y de los partidos políticos representados en el mismo. Como se expresa en la misma presentación del ente: "El IMMB dispone de dos herramientas fundamentales para modernizar los mercados: la nueva ordenanza municipal y los nuevos modelos de gestión. Una modernización que pasa por la mejora del Servicio de Mercados, el mantenimiento de la cuota comercial, la gestión de la diversidad y la unificación de la regulación del comercio. De esta manera, la actuación del IMMB se focaliza en tres campos: mejorar infraestructuras y servicios, actualizar la oferta comercial e incorporar políticas de promoción comercial"1.

La función del IMMB en estos últimos años ha sido la de modernizar los mercados municipales (con la reforma hoy en día de más del $70 \%$ de ellos), disminuyendo el número de paradas, eliminando aquellas que ofreciesen resultados económicos más moderados e intentando actualizar sus usos y servicios (internet, marketing, especialización, valor añadido...), manteniendo solamente aquellos negocios más competitivos y adaptados a las nuevas demandas (tanto de usuarios como, más tarde, y consecuentemente, de visitantes).

1 (cf. IMMB, 2017: http://www.mercatsbcn.com/). 
Cabe destacar, en este modelo, la evidente implicación pública en la gestión de los mercados, a la cual ha ido incorporando progresivamente la gestión privada (no sólo en relación con los comerciales y sus asociaciones, sino también incorporando grandes empresas, como las de supermercados, que se integran tras las reformas dentro de las estructuras de los mercados y que contribuyen a sufragar los gastos de los mismos).

El ejemplo de Barcelona ha tenido un cierto éxito internacional y ha sido puesto como ejemplo para distintas administraciones que han visto en la acción de esta ciudad un modelo a seguir en la promoción, recuperación y actualización de sus mercados. Podemos considerar que, en parte, este también ha sido el caso de Madrid, aunque con importantes particularidades propias. Así, la ciudad capital ha implementado, aunque más tardíamente, distintas acciones a lo largo de los últimos años que han ido enfocadas a la actualización y a la modernización de sus mercados, aunque con un resultado relativamente distinto en algunos casos. De este modo, se han implementado distintos planes, como el de innovación y transformación de los mercados municipales de Madrid (desde 2002-2003 y con secuelas hasta hace relativamente pocos años, 2012-2015), cuya intención era muy similar a la de las acciones emprendidas a partir de los años noventa por el IMMB: actualizar y modernizar los mercados, con un énfasis particular en las reformas arquitectónicas y comerciales de los mismos, incluyendo en buena parte la implicación de la empresa privada (sector supermercados, especialmente). Por otro lado, y como señalan Hernández Cordero y Andreeva (2016: 154), se han llevado a cabo cambios en la normativa que permiten introducir nuevos negocios no dedicados al comercio de alimentos (que puden ver reducida su presencia de un $65 \%$ a un $35 \%$ actualmente) y estableciendo que hasta $40 \%$ del espacio común podría ser usado para eventos, como degustaciones, sin que sea necesario pedir una licencia de esta nueva actividad. En este sentido, y en relación al tema que nos interesa destacar en este artículo y que desarrollaremos más tarde, es significativo el progresivo cierre de los puestos de venta de productos de alimentación en favor de espacios de restauración y tiendas gourmet (como puede verse claramente en mercados tales como San Miguel 0 San Antón).

Pero la principal diferencia con la gestión de los mercados de Barcelona es, sin lugar a dudas, la privatización de los mercados municipales que ha tenido lugar en los últimos años (en el apartado dedicado al Mercado de San Miguel nos referiremos de nuevo a este particular). Diversos organismos privados o personas, que en algunos casos son simplemente inversores y que hasta el momento no han tenido relación alguna con el sector, están reemplazando a las asociaciones de comerciantes en las titularidades de las concesiones, colocando los intereses privados por delante de los colectivos (incluyendo los asociativos) y dando como resultado una transformación muy importante de determinados mercados y que afecta tanto a sus usos y servicios como a su oferta, a su clientela y a la relación social y cultural que dichos mercados establecen con los barrios en los cuales se encuentran situados y de los cuales, se quiera o no, continuan siendo de algún modo un eje vertebrador.

\section{SI NO VAS A COMPRAR, ¿QUÉ INTERÉS TIENE VISITAR UN MERCADO?}

El turismo vinculado a la gastronomía, según la Organización Mundial del Turismo (OMT), "ha crecido considerablemente y se ha convertido en uno de los más dinámicos y creativos segmentos del turismo" (Leal, 2016:21; 0MT, 2012). Del mismo modo, y como señala Poulain (2007: 63), el patrimonio alimentario/gastronómico está asistiendo cada vez más a una puesta en valor desde el sector turístico que cada vez es más significativa a distintos niveles, entre los cuales el sociocultural y el económico.

Aquellos visitantes y turistas interesados de algún modo en lo gastronómico, acostumbran a prestar una atención especial a la cocina y a los productos locales y, cuando visitan un lugar, buscan "lo local", Io "auténtico" (Téchoueyres, 2007); en definitiva, aquello que, por un lado, no encuentra, 0 al menos, no de la misma manera, en su lugar de origen, y que es "diferente", incluso "exótico". Como destacan Hernández Cordero y Andreeva 
(2016: 150), "Tanto en Madrid como en Barcelona la revitalización de los mercados, sobre todo en el área central de las ciudades, ha implicado que los antiguos centros de abasto se vuelvan los baluartes de nuevos patrones de consumo que se engloban en la triada de lo auténtico, lo orgánico y lo natural".

Por otro lado, valoran también especialmente aquello que no es "turístico", es decir, que no ha sido "creado específicamente para el turista" (Medina, 2008). Aquello que muestra la vida local tal y como es 0 , al menos, como se piensa que es.

El mercado reúne ambos elementos en su estructura, y ello, en consecuencia, atrae a los visitantes (entendido este término de manera amplia, y no solamente relacionado con el turismo). En este sentido, el mercado puede recibir diariamente visitantes y turistas, quienes utilizan los recursos del mercado para otros fines que no sean la compraventa característica del mismo; unos fines que pueden ir desde el asistir a un taller nutricional 0 a una campaña de prensa, visitar las instalaciones 0 ir a comer 0 a cenar en los restaurantes del mercado.

Sin embargo, al no tratarse de una estructura específicamente turística, la relación entre el personal del mercado (vendedores, clientes...) y el visitante no siempre es fluida. Diversos factores influyen en esta relación: por un lado, el turista "visita" a su propio ritmo: observa, se detiene, admira, fotografía, toca, pregunta... Se convierte, en definitiva, desde el punto de vista del "local" —ocupe el lugar que ocupe en la estructura mercadal- en un elemento extraño que, en ocasiones, obstaculiza el paso, observa con detenimiento, fotografía mercancías, vendedores, clientes... Y puede suponer una cierta molestia 0 desencuentro en algunos casos, especialmente cuando la afluencia de clientes al mercado es masiva.

Una comerciante de la Boquería declaraba hace ya casi una década, en un artículo de prensa, que: "hoy todo se hace por el turismo y no nos identificamos". Igualmente — añade — nos encontramos "ante la presión de un turismo que compra muy poco"2.

2 La Vanguardia, cuaderno Vivir en Barcelona. Barcelona, domingo 1 de abril de 2007, p. 2.
A pesar de todo, la relación entre el mercado y el turista ofrece diferentes aspectos de interés que no pueden ser obviados: es una unión cada día más frecuente y en cierto modo inevitable, debido al atractivo que los mercados ejercen para el visitante foráneo. Los mercados, por su parte, evolucionan y se "transforman", adecuándose constantemente a las nuevas demandas sociales. Y el turismo es, sin duda, una de ellas.

De este modo vemos que los mercados han intentado, especialmente en los últimos años, aprovechar de algún modo este interés que - son conscientes - provocan en el turista. Así, por un lado, implementan esta atracción, pero, principalmente, intentan procurar que el turista pueda encontrar productos de su interés que le conviertan, además de visitante, en consumidor que pueda dejar un beneficio - no podemos olvidar que los mercados son conceptualmente puntos de venta-.

Dentro de este entramado de posible oferta, se encuentran también los restaurantes y los bares del mercado, que con los años han visto, en algunos casos, cómo cambiaba su tipo de cliente, desde alguien cercano al mercado que desayunaba $y / 0$ comía en sus instalaciones, a un público principalmente visitante 0 turista que hace cola en alguno de estos establecimientos para comer, cenar o simplemente tomar algo en el ambiente del mercado. Al mismo tiempo, los bares y restaurantes del mercado han aumentado en número y se han reestructurado para adaptarse a esta demanda creciente, y se encuentran entre el colectivo para el cual el negocio se ha incrementado de manera destacada con el aumento del turismo en los mercados.

\section{MERCADOS, CENTRALIDAD, VISITANTES Y RESTAURACIÓN: BARCELONA Y MADRID, BOQUERÍA Y SAN MIGUEL}

Los mercados se encuentran en lugares céntri$\cos$, bien conectados, de pueblos y ciudades y, por lo tanto, frecuentemente, en los cascos históricos 0 en los centros urbanos. Es precisamente esta centralidad de los mercados, esta posibilidad de sentir el pulso de una sociedad, de acercarse a sus gentes y a sus productos la que ha favorecido en los últimos 
años que los mercados se hayan convertido, por un lado, en centros de actividad municipal donde se ponen a prueba políticas públicas de todo tipo (promocionales, culturales, económicas y comerciales, arquitecturales...); y por otro, y más que nunca, en un reclamo turístico de primer orden.

La interrelación entre turismo y mercados está en franco crecimiento. La tendencia muestra que tanto la demanda como las posibilidades de oferta desde los mercados mismos siguen y seguirán aumentando (Medina, 2008; Black, 2007).

Evidentemente, no todos los mercados presentan el mismo interés para el visitante; ni siquiera, en ocasiones, interés para un visitante que no sea directamente comprador. Ni todos los mercados son iguales, ni son igual de centrales, ni venden necesariamente el mismo tipo ni la misma variedad, ni la misma calidad de productos, ni se encuentran en edificios patrimoniales, ni venden a los mismos precios, ni se encuentran igual de bien comunicados... Este hecho ha llevado a que determinados mercados a nivel internacional se hayan convertido en tótems turísticos (Rialto en Venecia o la Boquería misma, en Barcelona, son quizás los ejemplos más claros), mientras que otros llevan a cabo sus funciones en otros marcos sociales mucho más convencionales.

Nuestro interés en este artículo ha sido el de analizar dos de estas grandes estructuras como ejemplo de dos mercados centrales de dos ciudades importantes en el marco del Estado español. Dos mercados, la Boquería y San Miguel, fruto en parte el modelo del segundo del primero, ambos con trayectorias diferenciadas, pero que se han visto obligados a redefinir sus usos y sus servicios en función de nuevas demandas, tanto urbanas como directamente relacionadas con su clientela; y que pertenecen, como veremos, a dos modelos de gestión distintos que han dado resultados diferentes en cuanto a la aplicación de sus filosofías.

Del mismo modo, y en relación con el tipo de clientela que los visita y con el tipo de gestión de las instalaciones, nos interesa revisar, en ambos mercados, su utilización en tanto que lugares donde "comer fuera". Como señalan Warde y Martens (2000: 69). "Existen distintos tipos de lugares donde comer (fuera). Una pregunta importante es quién usa esos espacios y cuán a menudo lo hace". En el caso que nos ocupa, vemos que la respuesta a esta pregunta nos lleva hacia el turismo en tanto que fenómeno amplio, tanto de proximidad como de lejanía, y que lleva hasta los mercados a población no residente habitualmente, que lleva a cabo estancias más o menos cortas, y que transita y consume en la zona de manera ocasional. En relación con los mercados, nos interesa ver cómo el hecho de comer en el mercado desde la perspectiva actual ${ }^{3}$ ha influido también en (y se ha visto afectado por) las transformaciones más 0 menos recientes y el funcionamiento general del mercado como tal, en tanto que entidad comercial dedicada principalmente a la compra y venta de productos alimentarios al por menor.

\section{La Boquería: El buque insignia de la red de mercados municipales de Barcelona}

El mercado de Sant Josep de la Boquería es uno de los más renombrados internacionalmente (premio al mejor mercado del mundo otorgado por el Congreso Mundial de Mercados, celebrado en Washington DC en el año 2005) y parada obligada para la mayor parte de visitantes que llegan a Barcelona, además de para muchos barceloneses que lo visitan a diario o frecuentemente. Se ha escrito mucho sobre él, su historia y sus cualidades (Vázquez Montalbán, 2001; 0biols y Ferrer, 2004; Alsina y Arnàs, 2016). Antiguo mercado al aire libre, fue inaugurado oficialmente en 1840 y su cubierta de hierro data de 1914. A lo largo de los años, se ha convertido en el mercado más emblemático de Barcelona, así como un lugar de visita obligada para compradores y turistas.

Con 236 paradas de compraventa de alimentación, la Boquería cuenta en su interior con 9 bares y

3 Nos interesa destacar esta perspectiva actual ligada a la reciente modernización y transformación de los mercados, ya que, como señalaba uno de nuestros informantes en Boquería, en el mercado "se ha comido siempre", refiriéndose a los bares del mismo mercado, utilizados cotidianamente, y tanto antiguamente como hoy en día, por los mismos paradistas y algunos clientes para desayunar 0 comer. 
restaurantes (quince, si contamos los que se encuentran en la zona aledaña) que las dos remodelaciones de los años 1999-2000 y 2014-2015 han mejorado y aumentado. Tal y como el director del mercado expresa: "Mucha gente viene a diario a desayunar ${ }^{4} 0$ a comer aquí (a la Boquería) (...) Parte del movimiento del mercado durante el día se debe a esto"5. Una decena más de paradas permiten algún tipo de consumición in situ (principalmente zumos o fruta cortada y envasada). Pero, en total, el porcentaje de paradas que permiten este tipo de consumo directo (incluyendo bares y restaurantes) no supera el $10 \%$ del total de paradas del mercado.

La relación del mercado de la Boquería con la restauración es amplia y abarca distintos niveles. Por un lado, tenemos los restaurantes y bares históricos situados dentro 0 en los alrededores del mercado. Alguno de ellos, "instituciones" gastronómicas, no únicamente en el marco del mercado, si no en la ciudad en sí misma. Lugares como el "Pinotxo" o el "Quim" de la Boquería son suficientemente conocidos a nivel popular como para encontrarse entre los establecimientos más visitados. Algunos, como es el caso de los dos citados, disponen únicamente de la parada del mercado, como bar en si misma, ofreciendo dos o tres de sus cuatro lados como barra de bar, con asientos altos para la clientela. Nada más. Ello implica que las plazas no sean demasiadas, y que no sea extraño que se formen colas para ocupar un sitio, especialmente en las horas más críticas de la mañana y el medio día, aunque no solamente en esos horarios.

Es interesante, a este efecto, reproducir una de las notas del cuaderno de campo donde se da idea de este hecho de manera directa:

"Sentados en la barra del Quim de la Boquería, almorzando (....). Una pareja de mediana edad, locales, nos pregunta si tenemos para mucho. El bar está a tope de clientela, y no son los únicos que esperan a

4 La palabra "esmorzar" en catalán implica habitualmente aquella colación que se hace a media mañana, entre el desayuno y la comida. Hemos traducido aquí el término como "desayuno", ya que "almuerzo" en castellano tiene en ocasiones connotaciones de comida. El sentido de la palabra es, sin embargo, el que aquí aclaramos.

5 Entrevista. B-0U/13416. Traducida del catalán por el autor. que haya sitio. Les decimos que no, que un cuarto de hora como mucho. Nos dan amablemente las gracias y se esperan hasta que terminemos, lo que ocurre sobre quince minutos más tarde, después de pagar. Cuando nos vamos, ocupan nuestros sitios" 6 .

En segundo lugar, encontramos aquellos establecimientos, principalmente restaurantes, que se han establecido en el mercado (especialmente en su perímetro exterior, bajo las arcadas, en lo que es la Plaça de sant Josep, o en lugares adyacentes) en los últimos años, especialmente tras la reforma, y que se dirigen a un público amplio, desde los clientes y los visitantes del mercado hasta los turistas, ofreciendo una gama de productos principalmente de consumo rápido o medio, y que van desde recreaciones locales del fast-food y bocadillería hasta las ostras y/0 el marisco en raciones asequibles. Estos establecimientos, algunos de ellos con alguna firma importante 0 con uno 0 varios chefs "estrella" detrás (Carles Abellan, Romain Fornell...) cuentan con una importante clientela de turistas (superior en ocasiones a la de los bares del interior del mercado) mezclada con locales a distintas horas del día. Algunos de ellos han conseguido ponerse relativamente de moda y la afluencia de clientela es importante.

En un tercer nivel encontramos aquellos restaurantes que no se encuentran directamente en el perímetro del mercado, pero sí que tienen una cierta proximidad, principalmente en el barrio del Raval, pero también en el vecino Eixample, y que (anuncian que) usan producto del mercado en sus cocinas. Entre estos restaurantes encontramos algunos clásicos de Barcelona, como Ca l'Isidre o el Bar Cañete.

No es extraño encontrar casi a diario a algunos chefs de renombre, como el mismo Isidre Gironés, de Ca l'Isidre, pero también a Carles Gaig 0 al mismo Ferran Adrià en muchas ocasiones, y no sólo del pasado, mirando producto y comprando (y dejándose ver, al mismo tiempo) en el mercado. El producto de la Boquería es un reclamo para sus restaurantes y, 0 bien se anuncia directamente en los menús, 0 bien se establecen conexiones indirectas que favorecen dicha relación de cara al cliente. Tal y como

6 Diario de campo, 12 de abril de 2016, martes, 10:30 h. 
nos comentaba un jefe de cocina de un restaurante cercano al mercado: "(Nosotros) lo tenemos especificado en la carta. La gente (...) conoce la Boquería y es un referente, y para nosotros es importante que lo sepan (...)"7.

En este mismo sentido, podemos destacar la creación del proyecto EatBoquería, ligado al mercado y con un banner directamente desde su página web misma. Escrita directamente en inglés, la página nos dice:

Elige tu menú de mercado de la Boquería preparado con los mejores productos locales y exóticos del mercado de la Boquería, y disfruta de una experiencia gastronómica deliciosa y extraordinaria en Barcelona. Si estás de visita en Barcelona y eres un fan del producto de temporada y local, reserva uno de nuestros exquisitos menús EatBoquería, preparado con los productos más frescos del mercado de la Boquería $(\ldots)^{8}$

Los menús se sitúan entre los 55 y los 80 euros, y van dirigidos a un público principalmente foráneo, turista, utilizando el producto del mercado como reclamo directo. La página web se encuentra únicamente en inglés.

Todo lo expuesto nos lleva a un nuevo punto a tener en cuenta: entre un $30 \%$ y un $40 \%$ del producto a la venta en la Boquería va a la restauración. En este sentido, no hablamos únicamente de los restaurantes próximos, ni siquiera de los de la ciudad, sino de Cataluña en general (El Bulli de Ferran Adrià, en Roses, fue por ejemplo un importante cliente mientras estuvo en funcionamiento). En este sentido, y tal y como expresa el mismo director del mercado, este hecho es de gran relevancia y

(...) Permite que el mercado siga vendiendo producto (...) ¿Porqué Boquería?, porque saben que aquí encontrarán lo que necesitan (...) No cualquier mercado puede tener disponibles determinados productos en cualquier momento si no saben que es seguro que van a salir (...) Y en Boquería puedes

7 Entrevista. B-EM/04316.

8 http://eatboqueria.com/eat-boqueria-menus/. Traducción del inglés por el autor. encontrar lo que necesites, y sabes que lo tienen, porque todo el mundo viene a comprarlo aquí ${ }^{9}$

En este sentido, vemos cómo en Boquería, pese a una cierta deriva turística, a la transformación de determinadas paradas ofreciendo productos "interesantes para el turismo" y al peso de los restaurantes dentro del mercado, el mercado como lugar de venta de producto sigue teniendo un peso mucho más que significativo. Si a la venta a restaurantes le sumamos la venta online que algunas paradas han puesto ya en marcha y la compra que lleva a cabo la clientela diaria, vemos que el peso de la actividad comercial de compraventa de producto fresco y/o elaborado continua siendo muy principal. Y es por este hecho por el cual las discusiones internas y ciudadanas por la importante deriva turística que el mercado ha tomado, principalmente alrededor de la última década y media, se han hecho tan incisivas. Tanto, que el mismo mercado ha prohibido la circulación de grupos numerosos durante las horas y los días de mayor afluencia de clientes, considerando que la capacidad de carga del mercado en tanto que lugar de visita turística está más que superada ${ }^{10}$. En enero de 2017, el gobierno municipal ha implementado una medida de gobierno directamente dirigida al mercado de la Boquería ${ }^{11}$, y en la cual se ponen de manifiesto, principalmente, las dificultades de circulación propias del mercado, a las cuales hay que añadir las que proceden directamente de la amplísima afluencia turística ${ }^{12}$. Como medidas, se destaca, entre otras acciones, el esponjamiento de los espacios interiores de circulación del mercado; la limitación de los visitantes, especialmente por grupos; la introducción de distintos agentes cívicos, especialmente los fines de semana, que puedan dar información, controlar los flujos de gente y actuar contra conductas incívicas; control de "bares encubiertos" en las

9 Entrevista. B-0U/13416. Traducida del catalán por el autor.

10 Véase como un ejemplo entre otros muchos: http:// cadenaser.com/emisora/2015/04/08/radio_barcelona/1428478312_369488.html

11 https://es.slideshare.net/Barcelona_cat/mesura-degovern-sobre-mercat-de-la-boqueria-gener-2017

12 “(...) les dificultats per poder-hi comprar amb tranquil-litat, o l'excès de persones que visiten el mercat com una atracció i no com un punt d'abastiment (....)" (ibíd.) 
paradas que no tengan esta función, cambiando las superficies planas por superficies inclinadas que no permitan el consumo in situ. Todo ello, para continuar garantizando que la Boquería sigue siendo un mercado al servicio de la gente y de la ciudad, a pesar de las presiones que sin duda recibe y continuará recibiendo en el futuro ${ }^{13}$.

A pesar de ello, y como comentaba un paradista: "Boquería sigue siendo un mercado; no todo el mundo puede decir lo mismo"14. En las líneas que siguen, revisaremos el caso del mercado de San Miguel, en Madrid, como ejemplo de un tipo de gestión y de un resultado distinto del observado hasta el momento.

\section{San Miguel: hacia un nuevo concepto de mercado en Madrid}

Inaugurado como mercado cubierto el 13 de mayo de 1916, San Miguel es el único mercado en hierro que ha llegado hasta nuestros días en la capital, una vez desaparecidos los de La Cebada y Los Mostenses. Situado en la plaza de San Miguel con fachadas a la Plaza del Conde de Miranda y a la Cava de San Miguel, está considerado como Bien de Interés Cultural. Consta de una planta baja con estructura metálica de soportes de hierro fundido y un sótano para almacenes. Hoy en día, es un mercado de titularidad privada, que pertenece a la sociedad El Gastrónomo de San Miguel.

La web del propio mercado dice lo siguiente:

El Mercado de San Miguel (...) (tiene) el objetivo de aglutinar a los mejores comerciantes, profesionales, expertos y entusiastas de sus respectivas especialidades.

Son aquellos cuya oferta justifica el desplazamiento hasta el centro de Madrid, pero sin abandonar su vocación de mercado tradicional enfocado a la compra diaria. Una oferta vinculada a la calidad, a la frescura, y a la temporalidad de los alimentos,

13 La misma acción de gobierno mencionada pone en contexto la situación en el mercado con la situación de las Ramblas, vía en la cual se encuentra su entrada principal y que es, por autonomasia, el eje turístico de la ciudad (ibíd.).

14 Entrevista. B-JM/15416. La referencia a algunos mercados madrileños está implícita en la cita. respondiendo al reciente interés por la gastronomía que la ha convertido en un auténtico hecho cultural. El Mercado de San Miguel pretende llegar a ser un Centro de Cultura Culinaria, donde el protagonista es el producto, y donde tengan presencia activa todos los grandes hechos y acontecimientos del universo de la alimentación. Un lugar de encuentro, dirigido al cliente, al profesional, al gourmand, al que busca información y consejo. Un lugar dónde, además de hacer la compra cotidiana, se pueda participar en actividades, degustar lo que se va a llevar a casa 0 , simplemente, pasear 0 tomar algo. Un mercado tradicional con las ventajas de los nuevos tiempos"15.

Tras años de una cierta decadencia en las últimas décadas del siglo xx — debida, como señala Robles (2011: 104) a aspectos tales como la competencia de los supermercados y al vaciamiento y envejecimiento de esa zona de Madrid-y en los primeros años del siglo xxl, el mercado se reinaugura el 13 de mayo de 2009; una fecha de un cierto simbolismo, ya que el edificio se inauguró por primera vez el 13 de mayo de 1916.

Es curioso leer, tal y como ha aparecido también en varias de las entrevistas que hemos llevado a cabo, que en la presentación del Mercado de San Miguel en Wikipedia, se comenta que: "Su objetivo es resucitar y mejorar su actividad tradicional creando un mercado que tiene como referencia el de La Boquería de Barcelona"16.

Quizás uno de los aspectos más relevantes relacionados con el proyecto de San Miguel es que, partiendo en parte del caso de la Boquería, supone para Madrid, pero también para otros lugares de España, un nuevo modelo de "mercado" que cuenta con características que le son muy propias.

El mercado cuenta con 35 puestos:

-26 son directamente de restauración in situ;

— 6 son de restauración in situ más parada de venta de producto;

-1 tienda de cosmética;

-1 tienda de souvenirs turísticos.

15 http://www.mercadodesanmiguel.es/el-mercado/

16 Lo mismo encontramos en la noticia que el diario $E$ I País dedicó a su inauguración: "de plaza de barrio a espacio gourmet al estilo del barcelonés mercado de la Boquería". Cf. http://elpais.com/diario/2009/05/14/ madrid/1242300263_850215.html 
A esta lista, debe añadirse una pequeña parada que se dedica a vender entradas para un tablao flamenco próximo.

Vemos, a través de esta lista de paradas, como, a pesar de que en su página web el mercado afirma su nueva personalidad en tanto que lugar donde "degustar lo que se va a llevar a casa 0 , simplemente, pasear o tomar algo", pero "sin abandonar su vocación de mercado tradicional enfocado a la compra diaria", realmente casi el $100 \%$ de las paradas del mercado de San Miguel están abocadas a la restauración, al consumo in situ, e incluso aquellas paradas que venden realmente producto, lo hacen principalmente en tanto que degustación, dando al cliente la posibilidad de, además, llevarse el producto que le ha gustado o que desea.

Uno de los paradistas del mercado, que tiene además parada en la Boquería, entre otras, señalaba en una declaración que la parada de San Miguel es de las más rentables que posee; aunque, ciertamente, "el tipo de parada es muy diferente".

Una informante, vecina del mercado, nos afirma lo siguiente:

(...) Está bien para tomarse algo un día que tengas visitas, pero nada más. Comprar, no se puede comprar nada, primero porque casi no hay (...), un puesto de frutas, uno de carne y (otro de) quesos... Pero nada. Todo son bares. (...) Y aunque quisieras comprar, por mucho que quieras, los precios que tienen son prohibitivos $(\ldots)^{17}$

Otra informante, también vecina del barrio, añadía:

Comprar aquí, nada. Esto es para el turisteo. Si hay que comprar algo, aquí detrás hay un Dia, que es donde van algunos, y si no a las tiendas de más abajo. Al Mercado, para nada. Bueno, es que no es un mercado, en realidad $(\ldots)^{18}$

La declaración de la primera de ambas informantes nos lleva directamente sobre el fenómeno de gentrificación que ha sufrido y está sufriendo el barrio, y al cual la transformación del mercado ha

17 Entrevista. M-MCP/04516. Otra vecina, entrevistada por el diario El País el día de su inauguración, decía también lo siguiente: "No sé yo... Me parece que esto va a ser caro, caro" (Cf. http://elpais.com/diario/2009/05/14/madrid/1242300263_850215.html).

18 Entrevista. M-CP/05516. contribuido claramente: "Y aunque quisieras comprar, por mucho que quieras, los precios que tienen son prohibitivos (...)". Como señalan Hernández Cordero y Andreeva (2016: 146-147):

De esta forma, (los mercados) se rejuvenecen con la inclusión de locales de productos gourmet que suelen influir en la expulsión de las paradas de los comerciantes más precarios, quienes cuentan con menor capacidad económica para adaptarse a las nuevas demandas de consumo.

Las afirmaciones de ambas informantes nos llevan también sobre el tema de la visita turística. Tal y como hemos podido observar a través de nuestro trabajo de campo (todavía en curso) en dicho mercado, la mayor parte de las personas que recorren sus pasillos son turistas, bien extranjeros, bien de distintos lugares de España. En este sentido, el Mercado de San Miguel ha conseguido convertirse en un referente turístico de la capital, además de en uno de los lugares más o menos imprescindibles cuando se visita Madrid.

Si echamos, además, simplemente como ejemplo y sin otro ánimo que el de ofrecer otra perspectiva complementaria, un vistazo reciente a la página de critica gastronómica y hotelera TripAdvisor nos deja, únicamente en su primera página ${ }^{19}$, los titulares siguientes: "es un punto importante por conocer si eres turista"; "Bonito para visitar y para tomar una tapa"; "La comida, muy variada, sushi, ostras, platos castizos y el maridaje acorde a la oferta gastronómica".

Una de las recomendaciones, escrita por un madrileño, sirve para definir el espíritu de la mayor parte que se presentan:

Conozco este "Mercado" desde que era un crío, iba de vez en cuando con mi padre que era comerciante y la verdad es que desde la reforma no tiene nada que ver lo que era antes, un sitio que de un mercado de abastos que era se ha convertido en sitio obligado tanto para el turista como para la gente de Madrid que solemos ir de tapas por esta castiza ciudad, estuve el otro día después de tantos años sin

19 Solo de la primera página, como muestra, del día 28 de abril de 2016: https://www.tripadvisor.es/Attraction_Review-g187514-d1520183-Reviews-Mercado_ San_Miguel-Madrid.htmI\#review_367963870 
pisarlo (desde antes de la reforma) y me impresionó, tanto su carácter monumental como el comercial. Madrid ha ganado un sitio de tapas variado y distinto. Os lo recomiendo a todos los que paséis por la ciudad ${ }^{20}$.

Como señala Robles (2011: 105), "el mercado fue privatizado y puesto en manos de un grupo empresarial que ha transformado el mercado en centro gastronómico gourmet subordinado a un proyecto de restauración que oferta ocio y consumo orientado al servicio del turismo autóctono y extranjero". Igualmente, Hernández Cordero y Andreeva (2016: 149) comentan que: "En ambas ciudades (Barcelona y Madrid) los mercados son equipamientos públicos; sin embargo, en Madrid existe un proceso de desincorporación que ha empezado con la venta del de San Miguel, posteriormente transformado en mercado gourmet. Por otro lado, la tendencia de que el nuevo concesionario 'al expirar los acuerdos de gestión con las asociaciones de comerciantes' sea una única empresa ajena al mercado representa una nueva modalidad de (semi)privatización".

El modelo del mercado de San Miguel ha sido seguido por otros mercados del centro madrileño, como los de San Antón ${ }^{21}$ o San Bartolomé, que, junto con el primero, se han convertido en un lugar más de restauración tanto de día, como en la noche madrileña. Y es que, a diferencia del mercado de la Boquería, que abre oficialmente de 8 a 20:30 horas, el mercado de San Miguel abre entre semana de 10:00 a 24:00 horas, y los jueves, viernes y sábados, desde las 10:00 hasta las 2:00 de la mañana.

20 Ibíd.

21 A partir del año 2002, los veinte comerciantes adjudicatarios de las cincuenta bancas o puestos que constituían la Asociación de Comerciantes, comenzaron el largo proceso de reforma integral apoyándose más tarde en el Plan de Modernización y Dinamización de Mercados del Ayuntamiento de Madrid y del Plan FICO de la Comunidad de Madrid. En total ambas instituciones públicas cubrían a final de realización del proyecto el $35 \%$ del coste contratado en adjudicación. Sin embargo, la gran dimensión del proyecto, que exigía la demolición del edificio y su nueva construcción, era inalcanzable financieramente para la Asociación de Comerciantes, por lo que se incluyó una gran empresa 8grupo ECI) en la ecuación (cf. http://ecosistemaurbano. org/urbanismo/la-evolucion-de-los-mercados-municipales-el-caso-del-mercado-de-san-anton-madrid/).
El éxito de San Miguel se debe en buena parte a su originalidad: ofrecer un gran espacio de degustación y de restauración especializada en el interior patrimonial de un mercado emblemático de la parte más turística de Madrid. Si bien se han mantenido de manera visible un par de paradas que ofrecen producto fresco a la venta (una de ellas, la frutería, ocupa buena parte de una de las esquinas del mercado, frente a la cristalera), vemos que la totalidad de las paradas del mercado ofrecen productos para el consumo in situ, y en su gran mayoría, lo hacen de manera principal. Es decir, que, dejando de lado el puesto de cosmética —que, por cierto, también ofrece la posibilidad de tratamientos in situ- 0 la tienda de souvenirs o la venta de entradas para el tablao flamenco, ambas abocadas directamente a la clientela turística, no se trata de puntos de venta de producto, sino de consumo; es decir, de restauración. Y a este modelo corresponde tanto el tipo de público que recibe (en este caso, y sin disponer de más datos que los de nuestra propia observación, turistas y visitantes foráneos en su gran mayor parte), el tipo de producto que ofrece o los horarios de apertura.

Una visita curiosa al emblemático recinto podría hacer preguntarse al observador en relación a aquello que declaraba una informante citada anteriormente: "(...) Bueno, es que no es un mercado, en realidad (...)"22.

La reflexión del antropólogo José Ignacio Robles en su citado artículo sobre el mercado nos sirve como reflexión genérica sobre la transformación del Mercado de San Miguel:

El significado de determinados conceptos no es falsificable y no se puede ni se debe traficar con ellos: 0 mercado como centro de intercambio de productos de alimentación perecedera 0 centro gastronómico de ocio y turismo. 0 lugar de encuentro y vertebración del barrio 0 lugar de paso y citas esporádicas. 0 espacio de diversidad y competencia comercial 0 escaparate de una oferta complementaria. 0 libertad de acción y autonomía por parte del comerciante 0 subordinación a un modelo jerárquicamente establecido. En conclusión, o mercado de abastos — con todos sus defectos y virtudes - 0 centro de ocio gastronómico: la fórmula es innegociable y San Miguel ya eligió modelo. En

22 Entrevista. M-CP/05516. 
cierta forma, San Miguel es una muestra más de la capacidad innata de la ciudad de Madrid para crear símbolos, fagocitarlos y volver a reinventarlos, en un ejercicio sorprendente de vitalidad, imaginación y des-estructuración (Robles, 2011: 106).

\section{CONCLUSIONES}

A lo largo de este artículo hemos revisado dos modelos de oferta y de gestión ligada a dos mercados bandera en las ciudades donde se encuentran: el de Sant Josep de la Boquería en Barcelona, y el de San Miguel en Madrid.

Ambos mercados, situados en los centros históricos más patrimoniales y turistificados de ambas ciudades, se han convertido en paradigma, tanto de la gentrificación de sus actividades comerciales y de los barrios donde se encuentran, como de las importantes transformaciones y "actualizaciones" que algunos mercados están sufriendo en el momento actual, y que están modificando considerablemente aquello que hasta hace pocos años se consideraba que debía ser un mercado.

A pesar de las diferencias en los modelos municipales y/o privados de gestión y de actuación sobre ambos mercados, podemos observar tanto en uno como en otro caso la reproducción de algunos patrones similares. Tras las transformaciones impulsadas tanto en uno como en otro mercado, podemos observar que, aunque ambos modelos están en principio dirigidos a públicos distintos, se plantean desde estrategias municipales de promoción matizadas (Boquería pretende y reivindica en todo momento su servicio a la ciudad en tanto que mercado, y pone barreras y trabas al turismo; San Miguel se reconoce como espacio directamente turístico y promociona su papel como tal), y poseen estructuras de gestión distintas, ambos espacios se encuentran inmersos en un escenario articulado hoy en torno al turismo y al consumo cultural de productos gourmet, locales, artesanías culinarias, etc.

La deriva turística de un mercado como La Boquería se ha convertido en un tema de actuación prioritaria para el consistorio barcelonés. La división de opiniones entre aquellos adjudicatarios propietarios de paradas "tradicionales" frente a la de aquellos que han transformado las suyas en productos más fáciles de vender turísticamente, ha llevado a importantes discusiones tanto en el seno del mercado, como del IMMB y del ayuntamiento mismo. Sin embargo, dicha deriva responde - tal y como, por otro lado, señala la misma acción municipal propuesta- a causas que van más allá de las políticas municipales relativas a los mercados, los cuales se encuentran incardinados en las áreas urbanas de las cuales son ejes principales, y que en el caso de la Boquería son las áreas del Raval, el Gótico y la Ribera, dentro del distrito de Ciutat Vella, lugar de residencia, junto con el Eixample, de la mayor parte del turismo que visita la ciudad.

Ambos modelos han dado lugar, igualmente, a otras experiencias que han seguido uno u otro modelo: San Antón o San Bartolomé, en Madrid, para el caso de San Miguel, con una proyección directamente abocada al turismo y a la restauración; Santa Caterina en Barcelona o la Ribera en Bilbao, para el caso de Boquería, buscando un equilibro entre los usos y servicios tradicionales y las demandas turísticas; 0 bien a modelos híbridos entre ambas manifestaciones y que se están reproduciendo a lo largo y ancho de la geografía española.

Lo que sí que queda clara, tanto en uno como en otro caso, es la importancia y el poder de seducción que los mercados tienen hoy en día, tanto como atractivo turístico, como lugar donde "comer fuera", en un ambiente distinto, cercano a la venta del producto — principalmente fresco- y en un espacio patrimonial y que, hasta el momento, está mostrando ser un modelo de éxito en lo que a restauración se refiere. Sus derivaciones, sin embargo, todavía están por ver.

\section{BIBLIOGRAFÍA}

Alsina, M. y Arnàs, G. (2016). Mercats de Barcelona (seg/e XIX). Barcelona: Ajuntament de Barcelona/Albertí editor.

Black, R. (2007). Porta-Palazzo: The Market as a touristic attraction. In J. Tresserras, y F. X. Medina, (eds.) Patrimonio gastronómico y turismo cultural en el Mediterráneo. Barcelona: Universidad de Barcelona/Instituto Europeo del Mediterráneo. 
Denzin, N., Lincoln, I. (1994). Introduction. Entering the Field of Qualitative Research. In N. Denzin, \& I. Lincon. (eds.) Handbook of Qualitative Research (pp. 1-17). Thousand Oaks: Sage.

Domínguez, M., Coco, A. (2000). El pluralisme metodològic com a posicionament de partida. Una primera valoració del seu ús a la recerca social. Revista Catalana de Sociologia, 11, 105-132.

Guasch, 0. (1997). Observación participante. Madrid: Centro de Investigaciones Sociológicas.

Hernández Cordero, A., Andreeva Eneva, S (2016). Mercados, museus o malls: la gentrificación de los mercados municipales en Barcelona y Madrid. EntreDiversidades, primavera-verano, (pp. 143-174) http://contested-cities.net/wpcontent/uploads/2016/07/art5.pdf (Consultado el 23 de abril de 2017).

Krane, V., Baird, S. M. (2005). Using Ethnography in Applied Sport Psychology. Journal of Applied Sport Psychology, 17 (2), 87-107.

Kvale, S. (2007). Doing Interviews. London: Sage.

Leal, P. (2016). Turismo gastronómico: impulsor del comercio de proximidad. Barcelona: Editorial UOC.

Medina, F. X. (2008). Mercados urbanos en Europa: Patrimonio y promoción turística. In M. Álvarez y F. X. Medina (eds.) Identidades en el plato. EI patrimonio cultural alimentario entre Europa y América (pp. 207-220). Barcelona: Icaria.

Medina, F. X. (2015). Mercados y espacio público. Transformación y renegociación de nuevas demandas urbanas. Análisis comparativo de casos (Barcelona, Budapest, Buenos Aires). In Zainak. Cuadernos de Antropología-Etnografía, 36, 183-200. http://www. euskomedia.org/PDFAnlt/zainak/36/36183200.pdf

Montañés, M. (2009). Metodología y técnica participativa: teoría y práctica de una estrategia de investigación. Barcelona: UOC.

Taylor, S. J., Bogdan, R. (1998). Introduction to Qualitative Research Methods. New York: John Wiley and Sons.

Obiols, I., Ferrer, P. (2004). El Mercado de la Boquería: el pasado y el presente del mercado más emblemático de Barcelona. Barcelona: Edicions 62.
Poulain, J.-P. (2007). Los patrimonios gastronómicos y sus valorizaciones turísticas. In J. Tresserras, y F. X. Medina, (eds.) Patrimonio gastronómico y turismo cultural en el Mediterráneo. Barcelona: Universidad de Barcelona/Instituto Europeo del Mediterráneo, 39-72.

Robles, J. I. (2011). El mercado de San Miguel (Madrid), en Distribución y Consumo, julio-agosto, 103-106. http://www.mercasa.es/files/multimedios/1311869492_pag_103-108_mercadosanmiguel.pdf (consultado el 4 de abril de 2016).

Slater, T. (2012). Gentrification of the City. In Bridge, G. y Watson, S. (eds.), The New Companion to the City. Oxford: Blackwell, 571-585.

Téchoueyres, I. (2007). Patrimoine alimentaire et dynamiques territoriales: questionnements et exemples dans le Sud-ouest de la France. In J. Tresserras, y F. X. Medina, (eds.) Patrimonio gastronómico y turismo cultural en el Mediterráneo. Barcelona: Universidad de Barcelona/ Instituto Europeo del Mediterráneo, 243-268.

Vázquez Montalbán, M. (2001). La Boquería: la catedral dels sentits. Barcelona: Ajuntament de Barcelona.

Warde, A., Martens, L. (2000). Eating Out. Social differentiation, Consumption and Pleasure. Cambridge: Cambridge University Press.

Woods, P. (1986). Inside Schools: Ethnography in Educational Research. London: Routledge \& Kegan Paul.

F. Xavier Medina doctor en antropología social por la Universitat de Barcelona. Profesor y director de programas del área de alimentación y nutrición, Facultad de Ciencias de la Salud, Universitat Oberta de Catalunya (UOC), y director de la Cátedra UNESCO de Alimentación, Cultura y Desarrollo en la misma universidad. Investigador principal del Grupo de Investigación Interdisciplinar en Alimentación, Nutrición, Sociedad y Salud (UOC) y director del Grupo Interdisciplinar de investigación en Turismo (GRIT-EAE). Presidente de la International Commission on the Anthropology of Food and Nutrition (ICAF). Especialista en estudios de antropología de la alimentación. 